\title{
EVALUASI KINERJA INSTALASI FARMASI RUMAH SAKIT ISLAM PKU MUHAMMADIYAH PALANGKA RAYA KALIMANTAN TENGAH DENGAN PENDEKATAN BALANCED SCORECARD
}

\author{
Dewi Sari Mulia ${ }^{1}$ \\ 1Dosen Program Studi DIII Farmasi Fakultas IImu Kesehatan Universitas Muhammadiyah \\ Palangkaraya \\ Email: dewisarimulia@gmail.com
}

\begin{abstract}
ABSTRAK
Balanced Scorecard menerjemahkan misi dan strategi organisasi dalam tujuan operasional dan ukuran kinerja ke dalam empat perspektif, yaitu: perspektif keuangan, perspektif pelanggan, perspektif proses bisnis internal, dan perspektif pembelajaran dan pertumbuhan. Hasil penelitian menunjukkan untuk perspektif keuangan nilai TOR sebesar $13 x, \mathrm{ROI}$ sebesar 22\% dan Profit Margin sebesar 18\%. Dari nilai tersebut dapat disimpulkan bahwa kinerja keuangan IFRS sudah cukup baik jika dilakukan banchmark terhadap RS PKU Muhammadiyah Yogyakarta dan standar yang ditetapkan oleh LPPK Muhammadiyah. Untuk perspektif pelanggan yang diperoleh dari survei kepuasan pasien menunjukkan bahwa pasien puas dengan kinerja IFRS. Namun jika didasarkan pada peraturan mengenai standar pelayanan minimal di Rumah Sakit untuk indikator kepuasan pasien standar yang harus dicapai adalah sebesar $80 \%$, maka dapat disimpulkan bahwa kinerja IFRS masih perlu ditingkatkan lagi.Perspektif proses bisnis internal untuk indikator waktu tunggu pelayanan menunjukkan angka rata-rata sebesar 6 menit untuk resep non racikan dan 12 menit untuk resep racikan. Jika dibandingkan dengan standar pelayanan minimal di rumah sakit untuk indikator waktu tunggu pelayanan yang mempersyaratkan standar $\leq 30$ menit untuk resep non racikan dan $\leq 60$ menit untuk resep racikan, maka dapat disimpulkan bahwa kinerja IFRS PKU Muhammadiyah Palangka Raya untuk indikator waktu tunggu pelayanan sudah sangat baik. Penilaian terhadap indikator ketersediaan obat menunjukkan angka sebesar 98\% yang artinya bahwa IFRS masih memiliki tantangan untuk mencapai target tingkat ketersediaan obat sebesar $100 \%$. Perspektif pembelajaran dan pertumbuhan untuk indikator pelatihan karyawan menunjukkan bahwa $40 \%$ karyawan telah mendapatkan pelatihan pada tahun 2018.
\end{abstract}

Kata Kunci: Kinerja, IFRS, Balanced Scorecard.

\begin{abstract}
The Balanced Scorecard translates organizational mission and strategy into operational objectives and performance measures into four perspectives: financial perspective, customer perspective, internal business process perspective, and learning and growth perspective. The results showed that for a financial perspective the value of TOR 13 time, $R O I 22 \%$ and Profit Margin 18\%. From these values it can be concluded that IFRS financial performance is good enough if it is done by a banchmark towards PKU Muhammadiyah Yogyakarta Hospital and the standards set by the Muhammadiyah LPPK. For the customer perspective obtained from the patient satisfaction survey shows that patients are satisfied with the performance of IFRS. But if it is based on regulations regarding minimum service standards at the Hospital for standard patient satisfaction indicators that must be achieved is $80 \%$, then it can be concluded that the performance of IFRS still needs to be improved. The internal business process perspective for service waiting time indicators shows an average number of 6 minutes for prescription drug and 12 minutes for mixing prescription medication. When compared with the minimum service standards in hospitals for service waiting time indicators
\end{abstract}


that require a standard $\leq 30$ minutes for prescription drug and $\leq 60$ minutes for mixing prescription medication, it can be concluded that the performance of PKU Muhammadiyah Palangka Raya IFRS for service waiting time indicators is very good. Assessment of the indicator of drug availability shows a figure of $98 \%$, which means that IFRS still has the challenge of achieving the target level of drug availability of $100 \%$. The learning and growth perspective for employee training indicators shows that $40 \%$ of employees have received training in 2018.

\section{PENDAHULUAN}

Rumah Sakit adalah institusi pelayanan kesehatan bagi masyarakat dengan karakteristik tersendiri yang dipengaruhi oleh perkembangan ilmu pengetahuan kesehatan, kemajuan teknologi, dan kehidupan sosial ekonomi masyarakat yang harus tetap mampu meningkatkan pelayanan yang lebih bermutu dan terjangkau oleh masyarakat agar terwujud derajat kesehatan yang setinggi-tingginya ${ }^{1}$. Instalasi Farmasi adalah unit pelaksana fungsional yang menyelenggarakan seluruh kegiatan pelayanan kefarmasian di Rumah Sakit ${ }^{2}$. Standar Pelayanan Kefarmasian di Rumah Sakit meliputi standar: 1) pengelolaan sediaan farmasi, alat kesehatan, dan bahan medis habis pakai; dan 2) pelayanan farmasi klinik.

Kinerja adalah hasil kerja secara kualitas dan kuantitas yang dicapai oleh seorang pegawai dalam melaksanakan tugasnya sesuai dengan tanggungjawab yang diberikan kepadanya ${ }^{3}$. Tingkat keberhasilan suatu kinerja meliputi aspek kuantitatif dan kualitatif. Manajemen Kinerja adalah suatu ilmu yang memadukan seni di dalamnya untuk menerapkan suatu konsep manajemen yang memiliki tingkat fleksibilitas yang representatif dan aspiratif guna mewujudkan visi dan misi perusahaan dengan cara mempergunakan orang yang ada di organisasi tersebut secara maksimal ${ }^{4}$.

$$
\text { Pengukuran kinerja dengan }
$$
konsep Balanced Scorecard untuk sebuah organisasi atau perusahaan telah diperkenalkan oleh Kaplan dan Norton pada tahun 1996. Konsep ini merupakan alat manajemen kontemporer (contemporary management tool) yang dapat digunakan oleh perusahaan (termasuk rumah sakit) untuk menilai kinerja setiap elemen dalam struktur organisasi perusahaan. Oleh karena itu Balanced Scorecard menerjemahkan misi dan strategi organisasi dalam tujuan operasional dan ukuran kinerja ke dalam empat perspektif, yaitu: perspektif keuangan, perspektif pelanggan, perspektif proses bisnis internal, dan perspektif pembelajaran dan pertumbuhan ${ }^{5}$.

\section{Penggunaan konsep Balanced} Scorecard diharapkan dapat mengurangi kelemahan yang ada pada pengukuran kinerja yang hanya berorientasi pada aspek keuangan saja. Perbedaan yang 
terdapat dalam konsep ini adalah digunakannya informasi non keuangan sebagai alat ukur kinerja selain informasi keuangan sehingga tidak menekankan pada pencapaian tujuan jangka pendek saja melainkan dapat mengukur penyebab terjadinya perubahan sehingga kelemahankelemahan tersebut dapat diantisipasi. Penelitian ini diharapkan dapat menjadi bahan evaluasi bagi pihak manajemen Rumah Sakit untuk dapat meningkatkan kinerja Instalasi Farmasi Rumah Sakit menjadi lebih efektif dan efisien sehingga dapat mendukung peningkatan kinerja Rumah Sakit Islam PKU Muhammadiyah Palangka Raya sebagai satu-satunya Rumah Sakit Islam Swasta di Kalimantan Tengah.

\section{METODE}

Penelitian ini menggunakan rancangan penelitian studi kasus non eksperimental dengan pendekatan deskriptif eksploratif. Penelitian ini dimaksudkan untuk mengetahui kinerja Instalasi Farmasi Rumah Sakit Islam PKU Muhammadiyah Palangka Raya dengan pendekatan Balanced Scorecard yang ditinjau dari empat perspektif yaitu keuangan, perspektif pelanggan, perspektif proses pelayanan serta perspektif pembelajaran dan pertumbuhan. Kriteria data yang diperoleh adalah data kualitatif dan kuantitatif yang diperoleh dengan wawancara, survei dan observasi langsung terhadap data primer maupun data sekunder yang tersedia di
Instalasi Farmasi Rumah Sakit Islam PKU Muhammadiyah Palangka Raya.

\section{HASIL PENELITIAN DAN}

\section{PEMBAHASAN}

\section{Perspektif Keuangan}

Penilaian kinerja perspektif keuangan IFRS dapat dilihat dari beberapa indikator yaitu ITOR, ROI dan Profit Margin. Pengukuran ini diperoleh dari laporan keuangan IFRS pada tahun 2017 dan 2016. Hasil pengukuran kinerja IFRS dari perspektif keuangan dapat dilihat pada tabel 1.

Tabel 1. Kinerja IFRS dari Perspektif Keuangan Tahun 2018

\begin{tabular}{lccc}
\hline \multirow{2}{*}{ Indikator } & \multirow{2}{*}{ Rasio } & \multicolumn{2}{c}{ Benchmark } \\
\cline { 3 - 4 } & & Rasio & Standar \\
\hline TOR & $13 x$ & $27 x$ & $24 x$ \\
ROI & $22 \%$ & $9 \%$ & $15 \%-$ \\
Profit & $18 \%$ & $6 \%$ & $25 \%$ \\
Margin & & & $5 \%-$ \\
\multicolumn{2}{c}{ Sumber: data sekunder } & $20 \%$ \\
\hline
\end{tabular}

Cara terbaik dalam menentukan rasio ideal untuk hasil pengukuran kinerja keuangan adalah dengan membandingkan rasio yang diperoleh dengan usaha sejenis. Data yang digunakan sebagai pembanding adalah data analisis kinerja keuangan dari RS PKU Muhammadiyah Yogyakarta dan standar yang ditetapkan oleh LPPK Muhammadiyah.

\section{Perspektif Pelanggan}

\section{Tingkat Kepuasan Pasien}

\section{Uji validitas dan reliabilitas kuisioner}

Uji validitas dan reliabilitas dilakukan terhadap 30 kuisioner yang dibagikan 
Evaluasi Kinerja Instalasi Farmasi Rumah Sakit Islam PKU Muhammadiyah Palangka Raya Kalimantan Tengah Dengan Pendekatan Balanced Scorecard

kepada responden dengan kriteria Analisis Tingkat Kepuasan

sebagai berikut:

- Pasien atau keluarga pasien yang

Pengukuran tingkat kepuasan pada berusia 12 s/d 65 tahun (kategori masa remaja awal s/d lansia akhir menurut Depkes RI (2009).

- Menggunakan fasilitas ruang tunggu selama menerima pelayanan resep di IFRS.

- Bersedia untuk memberikan jawaban sesuai dengan pertanyaan dalam kuisioner.

Validitas item menggunakan SPSS dengan pendekatan korelasi Pearson (Pearson's Correlation) dan reliabilitas item di uji dengan pendekatan Cronbach Alpha. Hasil analisis menunjukkan bahwakorelasiPearson antaratiap item dengan item total memiliki nilai lebih besar dari tabel Pearson untuk signifikansi 2tailed level 0,01 dengan jumlah $\mathrm{N}$ sebanyak 30 yaitu sebesar 0,456. Berdasarkan hasil tersebut maka semua item dinyatakan valid. Sedangkan hasil analisis untuk reliabilitas item menunjukkan bahwa nilai Cronbach Alpha sebesar 0,780 yang artinya bahwa reliabilitas item dapat diterima. penelitian ini menggunakan format jawaban Skala Likert yang memungkinkan pasien menjawab dalam berbagai tingkatan (1-5) dimana setiap jawaban diberi bobot nilai dengan ketentuaan sebagai berikut ${ }^{6}$ :

Skor 5 bila jawaban "Sangat Puas"

Skor 4 bila jawaban "Puas"

Skor 3 bila jawaban "Cukup Puas"

Skor 2 bila jawaban "Tidak Puas"

Skor 1 bila jawaban "Sangat Tidak Puas"

Kriteria interpretasi skor menurut Skala Likert dalam pengukuran tingkat kepuasan adalah sebagai berikut:

Angka $0 \%-20 \%=$ Sangat

Tidak Puas

Angka $21 \%-40 \%=$ Tidak Puas

Angka $41 \%-60 \%=$ Cukup Puas

Angka $61 \%-80 \%=$ Puas

Angka $81 \%-100 \%=\quad$ Sangat Puas

Kuisioner dibagikan kepada 80 responden dengan kriteria yang telah disebutkan di atas. Hasil pengukuran terhadap tingkat kepuasan pasien dapat dilihat pada tabel 2. 
Tabel 2. Tingkat Kepuasan Pasien IFRS Tahun 2018

\begin{tabular}{|c|c|c|c|c|c|c|c|c|c|c|c|c|}
\hline \multirow{3}{*}{$\frac{\text { Item }}{1}$} & \multicolumn{10}{|c|}{ JumlahJawabanResponden } & \multirow{3}{*}{$\begin{array}{c}\text { Total } \\
309\end{array}$} & \multirow{3}{*}{$\begin{array}{c}\text { Persentase } \\
(\%)\end{array}$} \\
\hline & \multicolumn{2}{|c|}{ Skor 5} & \multicolumn{2}{|c|}{ Skor 4} & \multicolumn{2}{|c|}{ Skor 3} & \multicolumn{2}{|c|}{ Skor 2} & \multicolumn{2}{|c|}{ Skor 1} & & \\
\hline & 24 & 120 & 29 & 116 & 19 & 57 & 8 & 16 & 0 & 0 & & \\
\hline 2 & 22 & 110 & 34 & 136 & 16 & 48 & 8 & 16 & 0 & 0 & 310 & 78 \\
\hline 3 & 23 & 115 & 36 & 144 & 12 & 36 & 8 & 16 & 1 & 1 & 312 & 78 \\
\hline 4 & 22 & 110 & 29 & 116 & 18 & 54 & 5 & 10 & 6 & 6 & 296 & 74 \\
\hline 5 & 21 & 105 & 31 & 124 & 14 & 42 & 13 & 26 & 1 & 1 & 298 & 75 \\
\hline 6 & 19 & 95 & 26 & 104 & 20 & 60 & 9 & 18 & 6 & 6 & 283 & 71 \\
\hline 7 & 20 & 100 & 25 & 100 & 21 & 63 & 12 & 24 & 2 & 2 & 289 & 72 \\
\hline 8 & 25 & 125 & 33 & 132 & 13 & 39 & 9 & 18 & 0 & 0 & 314 & 79 \\
\hline 9 & 23 & 115 & 33 & 132 & 16 & 48 & 7 & 14 & 1 & 1 & 310 & 78 \\
\hline 10 & 25 & 125 & 29 & 116 & 15 & 45 & 10 & 20 & 1 & 1 & 307 & 77 \\
\hline 11 & 20 & 100 & 25 & 100 & 20 & 60 & 13 & 26 & 2 & 2 & 288 & 72 \\
\hline 12 & 16 & 80 & 27 & 108 & 21 & 63 & 12 & 24 & 4 & 4 & 279 & 70 \\
\hline 13 & 18 & 90 & 21 & 84 & 26 & 78 & 14 & 28 & 1 & 1 & 281 & 70 \\
\hline \multicolumn{12}{|c|}{ Rata-rata Persentase (\%) } & 75 \\
\hline & & & & Inte & ret & iSk & & & & & & Puas \\
\hline
\end{tabular}

Sumber: data primer yang diolah.

Standar pelayanan minimal rumah sakit yang diatur dalam Keputusan Menteri Kesehatan Republik Indonesia Nomor : 129/Menkes/SK/II/2008 menyebutkan bahwa standar untuk indikator kepuasan pelanggan adalah sebesar $\geq 80 \%$. Maka dengan demikian ketercapaian untuk indikator kepuasan pelanggan masih perlu ditingkatkan.

\section{Perspektif Proses Bisnis Internal Waktu Tunggu Pelayanan}

Perhitungan waktu tunggu pelayanan dimulai dari resep diterima oleh petugas sampai dengan sediaan diserahkan kembali kepada pasien. Hasil pengukuran mengenai waktu tunggu pelayanan IFRS untuk resep non racikan dan resep racikan dapat dilihat pada tabel 3 dan 4 .
Tabel 3. Waktu Tunggu Pelayanan IFRS untuk Resep Non Racikan

\begin{tabular}{llcc}
\hline No & $\begin{array}{c}\text { TanggalRes } \\
\text { ep }\end{array}$ & $\begin{array}{c}\text { Jumlah } \\
\text { Resep }\end{array}$ & $\begin{array}{c}\text { Rata- } \\
\text { rata } \\
\text { Waktu } \\
\text { Tunggu } \\
\text { (menit) }\end{array}$ \\
\hline 1. & 21 Agustus & 19 & 7 \\
\hline 2. & 22 Agustus & 46 & 5 \\
\hline 3. & 23 Agustus & 35 & 7 \\
\hline 4. & 24 Agustus & 25 & 8 \\
\hline 5. & 25 Agustus & 45 & 9 \\
\hline 6. & 27 Agustus & 35 & 4 \\
\hline 7. & 28 Agustus & 30 & 5 \\
\hline 8. & 29 Agustus & 35 & 6 \\
\hline 9. & 30 Agustus & 35 & 6 \\
\hline 10. & 08 Oktober & 35 & 3 \\
\hline 11. & 13 Oktober & 35 & 3 \\
\hline 12. 16 Oktober & 20 & 3 \\
\hline \multicolumn{3}{c}{ Total Rata-rata WaktuTunggu } \\
\multicolumn{3}{c}{ (menit) } & 6 \\
\hline
\end{tabular}

Sumber: data primer yang diolah. 
Evaluasi Kinerja Instalasi Farmasi Rumah Sakit Islam PKU Muhammadiyah Palangka Raya Kalimantan Tengah Dengan Pendekatan Balanced Scorecard

Tabel 4. Waktu Tunggu Pelayanan IFRS untuk Resep Racikan

\begin{tabular}{|c|c|c|c|}
\hline $\begin{array}{l}\mathbf{N} \\
\mathbf{0} .\end{array}$ & $\begin{array}{l}\text { TanggalR } \\
\text { esep }\end{array}$ & $\begin{array}{l}\text { JumlahR } \\
\text { esep }\end{array}$ & $\begin{array}{c}\text { WaktuTu } \\
\text { nggu } \\
\text { (menit) }\end{array}$ \\
\hline 1. & $\begin{array}{l}21 \\
\text { Agustus }\end{array}$ & 1 & 7 \\
\hline 2. & $\begin{array}{l}22 \\
\text { Agustus }\end{array}$ & 1 & 21 \\
\hline 4. & $\begin{array}{l}24 \\
\text { Agustus }\end{array}$ & 1 & 10 \\
\hline 5. & $\begin{array}{l}25 \\
\text { Agustus }\end{array}$ & 2 & 8 \\
\hline 6. & $\begin{array}{l}27 \\
\text { Agustus }\end{array}$ & 2 & 14 \\
\hline \multicolumn{3}{|c|}{$\begin{array}{c}\text { Raata-rata WaktuTunggu } \\
\text { (menit) }\end{array}$} & 12 \\
\hline \multicolumn{4}{|c|}{ Sumber: data primer yang diolah. } \\
\hline
\end{tabular}

Nomor:

129/Menkes/SK/II/2008 menyebutkan bahwa standar untuk indikator waktu tunggu pelayanan resep non racikan adalah $\leq 30$ menit, sedangkan untuk resep racikan $\leq 60$ menit. Maka dapat disimpulkan bahwa waktu tunggu pelayanan IFRS PKU Muhammadiyah Palangka Raya sudah memenuhi standar yang ditetapkan.

\section{Ketersediaan Obat}

Hasil pengukuran mengenai tingkat ketersediaan obat di IFRS dapat dilihat pada tabel 5 .

Tabel 5. Tingkat Ketersediaan Obat

\begin{tabular}{|c|c|c|c|c|c|}
\hline \multirow[b]{2}{*}{$\sum$ Resep } & \multirow[b]{2}{*}{ ¿Recipe } & \multicolumn{4}{|c|}{ SRecipe } \\
\hline & & TidakTerlayani & $\begin{array}{c}\text { Persentase } \\
(\%)\end{array}$ & Terlayani & $\begin{array}{c}\text { Persentase } \\
(\%)\end{array}$ \\
\hline 1117 & 3344 & 67 & 2 & 3277 & 98 \\
\hline
\end{tabular}

Sumber: data primer yang diolah.

Ketersediaan obat di Rumah Sakit selain dipengaruhi oleh manajemen siklus obat juga berkaitan erat dengan kepatuhan penulisan resep sesuai formularium yang menurut standar pelayanan minimal di rumah sakit adalah sebesar 100\%. Hasil penelitian menunjukkan bahwa terdapat $2 \%$ obat yang tidak terlayani oleh IFRS berdasarkan sampling terhadap 1117 resep pasien umum yang masuk pada periode Juli s/d Desember 2018.
Perspektif Pembelajaran dan Pertumbuhan Pelatihan Karyawan Menurut Peraturan Menteri Kesehatan Republik Indonesia Nomor 72 Tahun 2016 tentang Standar Pelayanan Kefarmasian di Rumah Sakit bahwa setiap staf harus diberi kesempatan untuk meningkatkan pengetahuan dan keterampilannya. Peran Kepala Instalasi Farmasi dalam pengembangan staf dan program pendidikan meliputi: menyusun program orientasi staf baru, pendidikan dan pelatihan berdasarkan kebutuhan pengembangan kompetensi 
SDM; 2) menentukan dan mengirim staf sesuai dengan spesifikasi pekerjaan (tugas dan tanggung jawabnya) untuk meningkatkan kompetensi yang diperlukan; 3) menentukan staf sebagai narasumber/pelatih/fasilitator sesuai dengan kompetensinya. Hasil penelitian mengenai pelatihan karyawan dapat dilihat pada tabel 6 .

\section{Tabel 6. Persentase Pelatihan Karyawan Tahun 2018}

\begin{tabular}{llccc}
\hline \multirow{2}{*}{ No. } & \multirow{2}{*}{ Kualifikasi } & \multicolumn{2}{c}{ Jumlah } & \multirow{2}{*}{ Persentase } \\
\cline { 3 - 4 } & Apoteker & SDM & MengikutiPelatihan & \\
\hline 1. & TTK & 5 orang & 3 orang & $75 \%$ \\
\hline 2. & TTK & 4 orang & $80 \%$ \\
\hline 3. & TenagaAdministrasi & 2 orang & - & $0 \%$ \\
\hline 4. & PembantuPelaksana & 1 orang & - & $0 \%$ \\
\hline \multicolumn{4}{r}{ Total Persentase } & $\mathbf{4 0 \%}$ \\
\hline
\end{tabular}

Sumber: data primer.

\section{DAFTAR PUSTAKA}

1. Departemen Kesehatan RI. 2009. Undang-Undang Republik Indonesia Nomor 44 tentang Rumah Sakit. Jakarta.

2. Departemen Kesehatan RI. 2016. Peraturan Menteri Kesehatan Republik Indonesia Nomor 72 tentang Standar Pelayanan Kefarmasian di Rumah Sakit. Jakarta.

3. Mangkunegara, Anwar Prabu. 2009. Manajemen Sumber Daya Manusia. Bandung: PT. Remaja Rosdakarya.

4. Fahmi, Irham. 2014. Analisis Laporan Keuangan. Bandung: Alfabeta.

5. Hansen, Don R. dan Mowen, Maryanne M. 2009. Akuntans imanajerial, Buku Kedua, Edisi Kedelapan. Jakarta: Salemba Empat.

6. Akdondan Riduwan. 2013. Rumus dan Data dalam Aplikasi Statistika. Bandung: Alfabeta.

7. Departemen Kesehatan RI, 2004. Keputusan Menteri Kesehatan Republik Indonesia Nomor 1197/Menkes/SK/X/2004 tentang Standar Pelayanan Farmasi di Rumah Sakit. Jakarta.

8. Departemen Kesehatan RI, 2008. Keputusan Menteri Kesehatan Republik Indonesia Nomor 129/Menkes/SK/II/2008 tentang Standar Pelayanan Minimal Rumah Sakit. Jakarta.

9. Departemen Kesehatan RI, 2009. Keputusan Menteri Kesehatan Republik Indonesia Nomor 1197/Menkes/SK/X/2004 tentang
Standar Pelayanan Rumah Sakit. Jakarta.

10. Departemen Kesehatan RI, 2010. Peraturan Menteri Kesehatan Republik Indonesia Nomor 340/MENKES/PER/III/2010 tentang Klasifikasi Rumah Sakit. Jakarta.

11. Departemen Kesehatan RI, 2012. Buku Panduan Hari Kesehatan Nasional. Jakarta.

12. Kaplan, R.S. dan Norton, D.P. 1996. Balanced Scorecard: Menerapkan Strategi Menjadi Aksi. Jakarta: Erlangga.

13. Kaplan, R.S. dan Norton, D.P. 2004. Strategy Maps: Converting Intangible Assets Into Tangible Outcomes. Boston: Harvard Business School Press.

14. Mahsun, Mohamad. 2006. Pengukuran Kinerja Sektor Publik. Yogyakarta: BPFE-Yogyakarta.

15. Munawir, S. 2004. Analisis Laporan Keuangan. Yogyakarta: Liberty.

16. Notoatmodjo, Soekidjo. 2012. Promosi Kesehatan dan Perilaku Kesehatan. Jakarta: RinekaCipta.

17. Srimindarti, C. 2006. Balanced Score card sebagai Alternatif untuk Mengukur Kinerja, http://www.stiestikubank.ac.id/, diakses 20 Juni 2018.

18. Wyatt, J. 2004. Score card, Dashboards and KPIS Key to Integrated Performance Management. Healthcare Financial Management. 